\title{
Multiple levels of chemokine receptor regulation in the control of mouse natural killer cell development
}

\author{
Giovanni Bernardini ${ }^{1}$, Giorgia Benigni ${ }^{1}$, Fabrizio Antonangeli ${ }^{1}$, Andrea Ponzetta ${ }^{1}$ and Angela Santoni ${ }^{1,2}$ \\ Laboratory of Molecular Immunology and Immunopathology, Department of Molecular Medicine, Istituto Pasteur-Fondazione Cenci Bolognetti, "Sapienza" \\ University of Rome, Rome, Italy \\ ${ }^{2}$ Neuromed, Pozzilli, Italy
}

Edited by:

Aurore Saudemont, University

College London, UK

\section{Reviewed by:}

Thierry Walzer, Centre International

d'Infectiologie, France

Guido Ferlazzo, University of

Messina, Italy

\section{*Correspondence:}

Giovanni Bernardini, Laboratory of Molecular Immunology and

Immunopathology, Department of Molecular Medicine, Istituto

Pasteur-Fondazione Cenci Bolognetti,

"Sapienza" University of Rome, Viale

Regina Elena 291, Rome 00161, Italy

e-mail: giovanni.bernardini@

uniroma1.it
Chemokines play a fundamental role in lymphocyte development, mainly attributable to the control of the correct localization in the proper microenvironments of cells undergoing maturation. Natural killer (NK) cell development occurs in the bone marrow (BM) where their localization is regulated by the balance of chemokine function in cell retention into tissues and mobilization into circulation. In addition, NK cells from several extra-medullary tissues are phenotypically and functionally different from their circulating counterpart suggesting that maturation can be completed in organs other than BM. Indeed, a role of chemokines in NK cell localization into tissues during homeostatic conditions is also documented. In this review, we summarize the current notion related to the relevance of several chemokine/chemokine receptor axes in NK cell development with a focus on the regulation of their expression and function.

Keywords: NK cell, chemokine receptor, transcription factors, microRNA, lymphocyte development and function, bone marrow

\section{GENERAL INTRODUCTION ON NATURAL KILLER CELL DEVELOPMENT}

Natural killer (NK) cells are innate lymphocytes that provide host protection against infectious diseases and cancer. NK cells recognize ligands expressed by infected and transformed cells through germline encoded activating receptors resulting in the killing of target cells and production of immunomodulatory cytokines (1).

Bone marrow (BM) represents the main site for NK cell development, providing a full array of stimuli organized in complex microenvironments and acting in concert to sustain NK cell differentiation. Starting from the classical distinction of a committed precursor (NKP: $\mathrm{Lin}^{-} / \mathrm{CD} 122^{+} / \mathrm{NK} 1.1^{-} / \mathrm{CD} 4 \mathrm{~b}^{-}$), an immature (iNK: NK1.1 $1^{+} / \mathrm{CD} 49 \mathrm{~b}^{-} \mathrm{CD} 11 \mathrm{~b}^{\text {low }} / \mathrm{CD} 51^{\text {low }}$ ) and a mature NK subpopulation (mNK: CD49b $\left.{ }^{+} / \mathrm{Ly}_{4} 4 \mathrm{~s}^{+}\right)$, the NK cell developmental process has been progressively dissected through a more detailed comprehension of the great cell diversity within each stage (2-4). Recent findings better characterize the lineage commitment process, with the identification of an earliest NK cell progenitor in mouse BM that links the CLP and the NKP $(5,6)$, and is characterized by the expression of the surface molecules CD127 (IL-7 receptor), CD244, CD27, and of the basic helix-loop-helix transcription factor (TF) Id2.

A key marker of the NK cell lineage is CD27, a member of the TNF receptor superfamily, whose expression, combined with the integrin chain CD11b, defines four sequential developmental stages: $\mathrm{CD} 11 \mathrm{~b}^{\text {low }} \mathrm{CD} 27^{\text {low }}, \mathrm{CD} 11 \mathrm{~b}^{\text {low }} \mathrm{CD} 27^{\text {high }}$, $\mathrm{CD} 11 \mathrm{~b}^{\text {high }} \mathrm{CD} 27^{\text {high }}$, and $\mathrm{CD} 11 \mathrm{~b}^{\text {high }} \mathrm{CD} 27^{\text {low }}$ subsets (7). As a final step, the most mature subset acquires the expression of the inhibitory receptor KLRG1 that defines a cell subset with reduced effector functions, decreased IL-15 responsiveness, and proliferative capacity (8). However, our group demonstrated that also this terminally differentiated subset is heterogeneous, since the expression of the chemokine receptor CX3CR1 characterizes an even later maturation stage with unique functional features and localization within BM microenvironments (9).

\section{TISSUE-SPECIFIC NK CELL MATURATION}

It is important to note that, beside the BM-driven maturation process, also extra-medullary sites contribute to guide NK cell development, thus generating tissue-specific NK cell subsets (Figure 1). NKPs have been found in murine thymus, spleen, liver, and lymph nodes (LN), but it is still unknown whether these cells are generated in situ or are recruited from BM. Hepatic $\mathrm{CD}_{49 \mathrm{~b}^{-} \mathrm{NK}}$ cells uniquely express the integrin chain CD49a and display the TNF-related apoptosis-inducing ligand (TRAIL), through which they can trigger cell death in susceptible targets (10-12). Although liver NK cell phenotype resembles that of immature cells, accumulating evidence suggest that $\mathrm{CD} 49 \mathrm{a}^{+} \mathrm{CD} 49 \mathrm{~b}^{-}$hepatic NK cells represent a resident population, able to mediate memory responses, and correspond to a different subset compared to BM iNK, whereas $\mathrm{CD}_{4} 9 \mathrm{a}^{-} \mathrm{CD} 49 \mathrm{~b}^{+}$hepatic NK cells are a migratory subset that mostly originate outside the liver (12). More controversial is the stability of the CD49b ${ }^{-}$hepatic subset, as adoptive transfer experiments allowed some groups to demonstrate that this population can repopulate several organs and give rise to $\mathrm{CD} 49 \mathrm{~b}^{+}$cells $(10,13)$, while others evidenced that $\mathrm{CD} 4 \mathrm{~b}^{-}$cells are a stable subset that can only repopulate liver (12). An alternative pathway of NK cell development takes place in the thymus (14), generating a phenotypically and functionally distinct subset characterized by the expression of the $\alpha$-chain 


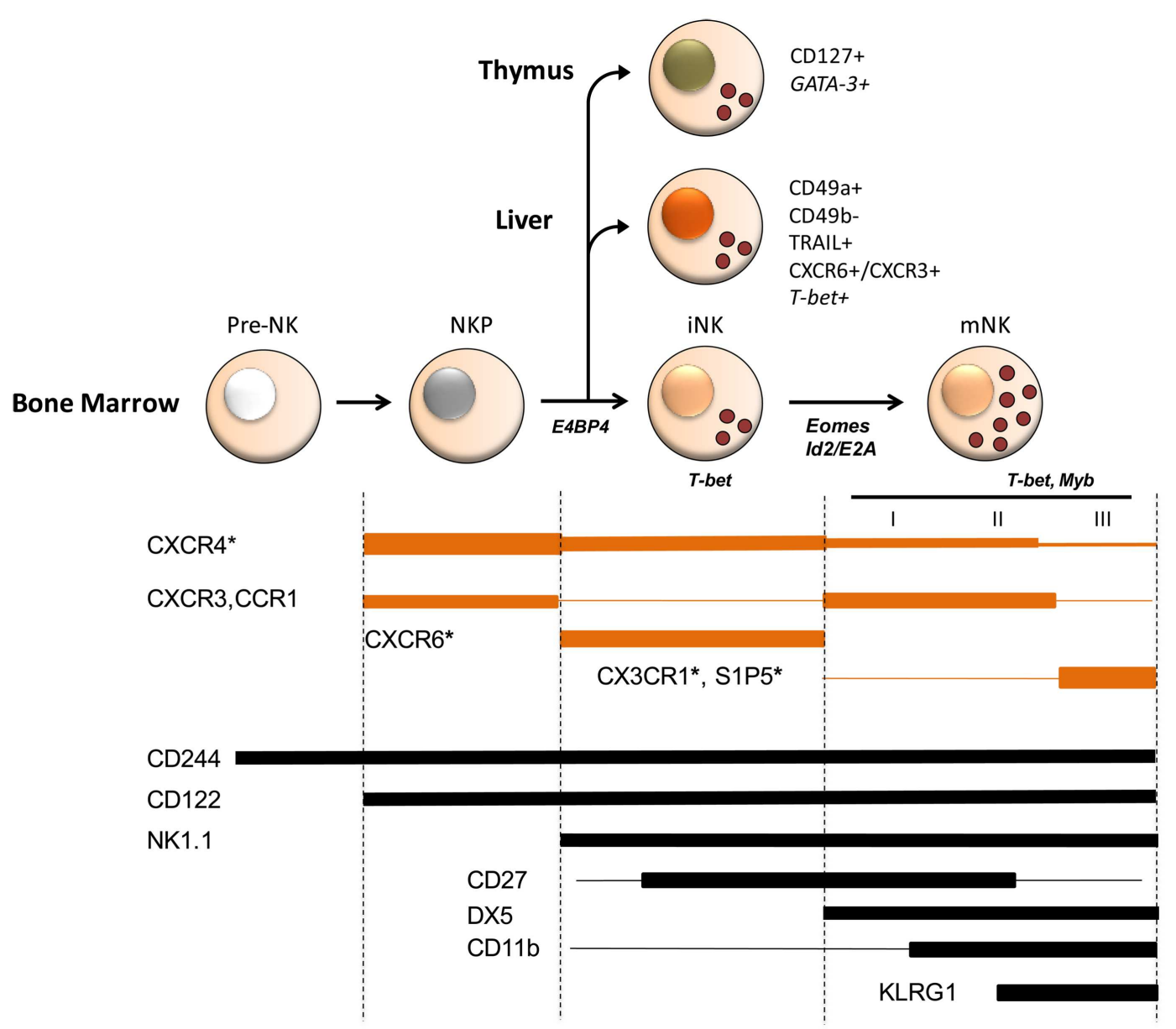

FIGURE 1 | Schematic model of chemoattractant receptor expression during mouse NK cell development and of transcription factors involved in NK cell commitment and maturation. Several stages of differentiation have been defined during which NK cells progressively acquire maturation markers (2-4). Three stages (I-III) corresponding to different levels of functional competence were described in mature CD49b+ (DX5+) NK cells being $C D 27^{\text {high }} \mathrm{CD} 11 \mathrm{~b}^{\text {low }}$ and $\mathrm{CD} 11 \mathrm{~b}^{\text {high }} \mathrm{CD} 27^{\text {high }}$ fully competent and a later stage of differentiation marked by the inhibitory receptor KLRG1 having reduced functional capacity. Besides $\mathrm{mNK}$, iNK are found in peripheral tissues, such as liver and thymus, where they represent NK cells with tissue-specific phenotype and functions possibly arising from a BM precursor. Chemokine and S1P receptor expression is developmentally regulated and is associated to selective functions in NK cell localization and maturation in BM. For example, CX3CR1 and $\mathrm{S}_{1} \mathrm{P}_{5}$ play an important and non-redundant role in mature NK cell egress from BM. Although, it is not known whether these two receptors are co-expressed by the same cell or expressed by different cell populations, prompting an investigation on how they co-operate to allow the efficient export of NK cells into circulation. Chemokine receptor expression overlaps that of several transcription factors active during NK cell development. Indeed some of these transcription factors, including T-bet and Myb were shown to directly affect chemokine and S1P receptor expression. Shown are transcription factors at the stage where they play a role in development. Asterisks identify chemoattractant receptors whose deficiency affects NK cell development. Line width is proportional to expression levels. of CD127 and high amounts of the TF GATA-3. The authors reported that $\mathrm{CD} 127^{+} \mathrm{NK}$ cells also constitute a relevant fraction of NK cells in $\mathrm{LN}$ that may arise from thymus due to their CD $11 b^{\text {low }}{ }^{-} D 16^{-}$CD $69^{\text {high }}$ Ly49 ${ }^{\text {low }}$ phenotype and to their selective reduction in athymic nude Foxn ${ }^{-1-}$ mice. Nevertheless, other authors found normal number of $\mathrm{CD}_{12} 7^{+} \mathrm{NK}$ cells in $\mathrm{LN}$ of Foxn $^{-1-}$ mice (15).

\section{REGULATION OF GENE EXPRESSION IN DEVELOPING NK CELLS}

Although the differential expression of maturation-related surface markers can help to distinguish different stages of development, the precise sequence and combination of stimuli controlling $\mathrm{NK}$ cell acquisition of functional properties, organ-specific features, inter-organ and intra-organ positioning, and chemokine receptor expression require further investigation. One critical aspect related to NK cell development is the transcriptional and posttranscriptional regulation of mRNA expression of molecules associated with developing NK cell phenotype and function. Several TFs and, more recently, selected microRNA (miRNA) expression were shown to be involved in the commitment to the NK cell lineage and in NK cell maturation (16-18) (Figure 1).

E4-binding protein 4 (E4BP4), is a basic leucine zipper (bZIP) TF required for NK cell development and maturation as its deficiency leads to marked reduction of iNK and lack of $\mathrm{mNK}$, without affecting other hematopoietic cell lineages (19). E4BP4 promotes 
the expression of Id2 and GATA-3, and forced expression of Id2 in E4BP4-deficient mice partially rescued the NK cell deficiency. Nevertheless, Id2 plays a critical role only for differentiation to mNK $(19,20)$. Gordon et al. demonstrated that the shift from immature $\mathrm{TRAIL}^{+} \mathrm{CD} 11 \mathrm{~b}^{\text {low }}$ to $\mathrm{CD} 49 \mathrm{~b}^{+} \mathrm{CD} 11 \mathrm{~b}^{\text {hi }} \mathrm{NK}$ cells and the parallel induction of Ly49 receptors in BM and liver require the expression of Eomesodermin (Eomes), a member of the T-box family of TFs (13). In this regard, a subset of less mature TRAIL ${ }^{+}$ NK cells that lacks CD49b and Eomes expression is expanded in neonates, and preferentially resides in adult liver $(10,21)$. It has been proposed that Eomes-dependent maturation is restricted by the TF T-bet in Eomes ${ }^{-} \mathrm{CD}_{49}{ }^{-}{ }^{-}$iNK as NK cells with T-bet deletion exhibit increased levels of Eomes expression and accelerated maturation (13). Nevertheless, T-bet is still expressed in Eomes ${ }^{+}$ mature NK cells, suggesting that other factors expressed in $\mathrm{mNK}$ cells circumvent T-bet to up-regulate Eomes expression (22).

Concerning miRNAs, conditional knockdown of the miRNAprocessing enzyme Dicer, which leads to a global impairment of the miRNA biogenesis, results in decreased mature NK cell number due to increased apoptosis of peripheral NK cells and accumulation of immature NK cells (18). Accordingly, significant accumulation of more immature $\mathrm{CD} 27^{\text {high }} \mathrm{CD} 11 \mathrm{~b}{ }^{\text {low }}$ and a related decrease of IFN- $\gamma$ production have been observed also within miRNA$150^{-1-}$ NK cells (23). This was associated to higher stability of the TF c-Myb, a direct target of miRNA-150 negatively regulated during the transition from $\mathrm{CD} 27^{\text {high }} \mathrm{CD} 11 \mathrm{~b}^{\text {low }}$ to $\mathrm{CD} 27^{\text {low }} \mathrm{CD} 11 \mathrm{~b}$ high NK cells (7). Similarly, miRNA-155 has been shown to enhance IFN- $\gamma$ production in human NK cells activated by IL-2/IL-18 (24). Differently from miRNA-150, in miRNA- $155^{-1-}$ mice, the immature CD27 ${ }^{\text {high }} \mathrm{CD} 11 \mathrm{~b}^{\text {low }} \mathrm{Ly} 49 \mathrm{D}^{-} \mathrm{Ly}_{49 \mathrm{H}^{-}} \mathrm{NK}$ cell subset is reduced, likely because miRNA-155 targets the pro-apoptotic factor Noxa, thus supporting survival and homeostasis of developing NK cells (25). In human, miRNA-181 expression increases during NK cell maturation and promotes NK cell differentiation by regulating Notch signaling, essential for lymphocyte development (26).

\section{CHEMOKINES AND LYMPHOCYTE DEVELOPMENT}

Chemokines are small cytokines with pleiotropic functions, having effect on a broad range of leukocytes and are thus critical regulators of immune cell function (27). Based on the presence of conserved cysteine residues, there are two major (CXC and $\mathrm{CC}$ ) and two minor ( $\mathrm{C}$ and $\mathrm{CX} 3 \mathrm{C}$ ) chemokine classes and accordingly four classes of chemokine receptors (CXCR, CCR, CX3CR, XCR). Another chemoattractant, the lipid sphingosine1-phosphate $(\mathrm{S} 1 \mathrm{P})$ and its receptors $\left(\mathrm{S}_{1} \mathrm{P}_{1-5}\right)$ are required for lymphocyte egress from lymphoid organs (28).

The chemokine system regulates the process of lymphocyte generation, mainly by directing developing cell positioning in successive compartmental niches, which provides exposure to specialized microenvironments in primary lymphoid organs. The leading chemokine/chemokine receptor axis in hematopoiesis is CXCL12/CXCR4, which regulates hematopoietic stem and progenitor cell homing to $\mathrm{BM}$, retention in specialized niches, proliferation, and egress to the circulation $(29,30)$.

In regard to B cell lymphopoiesis, CXCL12/CXCR4 axis is widely known to be crucial to maintain homeostatic levels of $\mathrm{B}$ cell precursors in the proper BM anatomical sites (31-33).
More recently, a finely regulated post-receptor signaling was also reported: in vitro long-term exposure of pro-B cells to CXCL12 induces their strong and sustained adhesion to VCAM-1, resulting in prolonged CXCL12-induced focal adhesion kinase (FAK) phosphorylation in immature cells, and promotion of progenitor cell growth, survival, and differentiation $(34,35)$. As long as cells differentiate, CXCL12-induced FAK phosphorylation becomes shortlived, decreasing adhesiveness of mature cells, and enhanced exit in peripheral circulation. Besides this, changes in scaffold proteins in cytosol or membrane and in the glycosylation pattern of CXCR4 occur during B cell maturation (36).

Concerning $\mathrm{T}$ cell maturation, it is well-established that CLPs generated in BM reach the thymus through venules in the corticomedullary junctions, where their maturation process is regulated by chemokine-driven migration from medulla toward outer cortex and subcapsular zone, with a leading role for CCL19CCL21/CCR7, CCL25/CCR9, and CXCL12/CXCR4 axes (37). In addition, CXCR4 acts on early thymocyte development as costimulator of the pre-TCR, providing MAPK and PI3K-dependent survival signals, and promoting the double negative (DN) 3 to DN4 transition $(38,39)$. Recently, a crucial role in T cell selection and development for the atypical receptor CCX-CKR has also been documented, linked to its function as decoy/scavenger receptor for CCR7 and CCR9 ligands (40).

In regard to NKT cells, development starts in thymus and is completed in peripheral tissues, mainly in liver, where an important role was recently attributed to CXCL16/CXCR6 axis. Absence of CXCR6 leads to reduced number of mature NKT cells in liver and accumulation of immature cells in BM and spleen, due to altered trafficking and impaired maturation of thymus-derived cells (41).

\section{REGULATION OF CHEMOKINE RECEPTOR EXPRESSION IN NK CELL DEVELOPMENT}

Accumulating evidence indicates that the chemokine system can influence NK cell development through the regulation of several aspects of NK cell biology (42). NK cells change their chemokine receptor expression profile during development in BM (Figure 1). CXCR4 is highly expressed by NKP but its expression progressively decreases on iNK and $\mathrm{mNK}$. On the other hand, CXCR3 and CCR1 are up-regulated on $\mathrm{CD} 49 \mathrm{~b}^{+} \mathrm{KLRG}^{-}{ }^{-} \mathrm{mNK}$. CX3CR1 and the chemoattractant receptor $\mathrm{S}_{1} \mathrm{P}_{5}$ are prevalently present on more differentiated NK cells, being the expression of CX3CR1 mainly confined to the KLRG1 ${ }^{+}$subset that poorly expresses CXCR4 and CXCR3 $(9,43,44)$. CXCR6 is expressed only by immature cells, a phenotype that is maintained also by liver resident CD49b ${ }^{-}{\text {Ly } 49^{-}}^{-}$ NK cells

NK cell development is severely impaired in CXCR4 conditionally deficient adult mice where NK cells are markedly reduced in number and display reduced cytotoxic function and IFN- $\gamma$ production capacity (45). The defect was associated with reduced number of NK cell precursors and decreased proliferation rate of CXCR4 deficient iNK. Of note, this effect could be related to regulation of developing $\mathrm{NK}$ cell maintenance into maturation niches, as we previously demonstrated that CXCR4 differentially affects $\mathrm{NK}$ cell retention into $\mathrm{BM}$ according to their maturation stage $(9,44)$. Accordingly, transient CXCR4 desensitization 
within BM promotes NK cell exit, likely facilitating the mobilizing effect of other chemoattractant receptors (46). In this regard, it was demonstrated that a fraction of CXCL12 abundant reticular (CAR) cells that express high levels of CXCL12, co-express IL-15 and IL-15Ralpha and can be found in close proximity with NK cells in vivo, thus suggesting that CAR cells trans-present IL-15 and provide CXCL12 to NK cells during development (45). The same authors also evidenced that CXCL12 enhances the effect of IL-15 on mNK cell generation from lymphoid precursors and iNK cells in vitro, suggesting that CXCR4 acts as a co-stimulus during NK cell differentiation.

Reduced NK cell number in several tissue compartments and impaired killing capacity of NK cells were also evidenced in CCR5 but not in CCR1 deficient mice under normal conditions. The defect was attributed to a slight reduction of NK cell precursor number and to a lower in vivo proliferation capacity of CCR5 deficient NK cells. The authors suggested that reduced number of proliferating NK cells may result either from incorrect localization of these cells in their specific niche or from deficiency in co-stimulatory signals provided by CCR5 (47).

Because CX3CR1 is expressed by a small fraction of mouse NK cells, to evaluate its role under physiological conditions we recently made use of a CX3CR1-GFP reporter mouse, where GFP is expressed under the control of CX3CR1 promoter. The subset identified by means of GFP expression, was expanded in all analyzed tissues of CX3CR1-deficient mice indicating that CX3CR1 regulates the homeostatic number of NK cells (48). A role of the CX3CR1 in NK cell maturation was also suggested, as NK cells from CX3CR1-deficient mice displayed a more pronounced degranulation capacity and mobilization from BM into blood, respectively after in vitro and in vivo activation. The increased number of CX3CR1-deficient NK cells in BM could be associated to their reduced exit in circulation by competitive adoptive transfer experiments. Similarly, $\mathrm{S} \mathrm{P}_{5}$ provides an egress signal to $\mathrm{NK}$ cells, allowing their export from the BM and the LNs (43).

Using CXCR6-GFP reporter mice, Paust et al. demonstrated that CXCR6 is important for the development and/or survival of $\mathrm{CXCR}^{+} \mathrm{NK}$ cells exclusively in the liver. CXCR6 ${ }^{-1-}$ mice have significantly reduced $\mathrm{GFP}^{+}$cells in liver, compared to $\mathrm{CXCR6}^{+/-}$mice, but normal number of $\mathrm{GFP}^{-}$cells. The authors were able to show that the phenotype observed is not due to altered trafficking, but is likely due to the absence of CXCR6mediated NK cell localization/survival in sinusoidal endothelium, which constitutively presents CXCL16 (49).

How are the effects of multiple chemokine receptors regulated, to finely tune the different steps of NK cell maturation? One level of control is the differential expression of chemotactic ligands by BM cellular niches. Of note, beside CXCL12, other chemokines are expressed in BM, although their cellular sources are less clear. Human BM stromal cells express CCL2, CX3CL1, and CXCL8, and, more specifically, osteoclasts can produce CCL5 and CCL9 during steady state $(50,51)$. A similar pattern of chemokine expression can be detected in mouse BM $(48,52)$. However, responsiveness to the chemokine environment requires an efficient control of chemotactic receptor gene expression, which represents a second mechanism of regulation. Interestingly, miR-150 knockdown significantly increased CXCR4 expression in mononuclear hematopoietic cells and affected their BM localization (53). It is likely that the effect of miR-150 on CXCR4 mRNA expression is Myb-dependent as this TF can associate the CXCR4 gene promoter and activate a CXCR4 reporter gene in transfection assays. Similarly to CXCR4, Myb expression decreases during NK cell maturation paralleling the increased expression of miR-150, thus suggesting that reciprocal regulation of these three factors plays a critical role in NK development during homeostasis. Regulation of CXCR4 function by miRNAs may also occur at the signaling level as another regulator of NK cell development, miR-181, was shown to repress PTEN expression in NKT cells thus allowing proper CXCL12-stimulation of Akt without affecting CXCR4 expression during thymic development (54).

Regulation of chemoattractant receptor expression by TFs in developing NK cells was also documented. T-bet promotes expression of $\mathrm{S}_{1} \mathrm{P}_{5}$ but not $\mathrm{S}_{1} \mathrm{P}_{1}$ by $\mathrm{mNK}$, and its deficiency leads to impaired CXCR3 expression (55). Interestingly, Eomes ${ }^{-}$and Eomes ${ }^{+}$NK cells express different repertoires of homing receptors consistent with their preferential anatomic localization (liver versus $\mathrm{BM}$ respectively) thus allowing the correct maturation of liver versus BM NK cell populations (13). Indeed, CD49b ${ }^{-}$Eomes $^{-} \mathrm{NK}$ cells expressed the integrin chain $\alpha_{\mathrm{V}}$ and the chemokine receptors CXCR3 and CXCR6 at greater levels relative to Eomes ${ }^{+}$NK cells and expressed substantially lower levels of the S1P receptors S1P1 and S1P5 than Eomes ${ }^{+}$NK cells. As we could not detect CXCR3 on $\mathrm{CD}_{49 \mathrm{~b}^{-}}\left(\mathrm{DX}^{-}\right) \mathrm{NK}$ cells in BM and spleen, expression of CXCR3 by this subset may be a unique property of hepatic NK cells (44). CXCR3 and CXCR6 expression in liver was linked to Eomes expression as repression of this TF caused re-expression of these chemokine receptors. Thus, Eomes and T-bet may regulate the differential expression of chemokine receptors at different stages of NK cell development.

ID proteins are essential for NK cell development and maturation, thanks to their ability to inhibit E-protein and in particular E2A, a family of TFs that act as transcription activators or repressors $(20,56)$. Id 2 and E2A have been suggested to regulate emigration of NK cells from the BM as Id $2^{-l-} \mathrm{E} 2 \mathrm{~A}^{-l-} \mathrm{mNK}$ number was reduced in peripheral blood but was normal in BM. Although in Id $2^{-1-} \mathrm{E} 2 \mathrm{~A}^{-1-}$ mice, $\mathrm{mNK}$ fail to express the adhesion molecule CD11b, no defect in chemokine receptor expression, i.e., CCR1, CCR5, or CX3CR1 could be observed. Nevertheless, a regulation of chemokine receptor expression by E2A is possible as CCR7 expression may depend on ID protein-mediated E-protein downregulation in thymocytes (57). Although mouse NK cells do not express CCR7, this mechanism of transcription may be relevant in humans where CCR7 plays a role in the localization of the NK cells in LN.

All together the studies presented herein evidence an emerging role of chemoattractant receptors in NK cell development. Thus, the identification of the molecular factors that regulate expression and function of these receptors and of BM niches where they can find and respond to their respective ligands will undoubtedly expand our comprehension of NK cell biology in the future.

\section{ACKNOWLEDGMENTS}

The authors' research is supported by grants from the Associazione Italiana per la Ricerca sul Cancro (an Investigator grant and Special 
Program Molecular and Clinical Oncology - 5 per Mille) and by grants from the Ministero dell'Istruzione, dell'Università e della Ricerca (MIUR-FIRB) Futuro in Ricerca and grant MIUR-L.297 FAR, and from the Italian Institute of Technology.

\section{REFERENCES}

1. Lanier LL. Up on the tightrope: natural killer cell activation and inhibition. Nat Immunol (2008) 9:495-502. doi:10.1038/ni1581

2. Dorfman JR, Raulet DH. Acquisition of Ly49 receptor expression by developing natural killer cells. J Exp Med (1998) 187:609-18. doi:10.1084/jem.187.4.609

3. Rosmaraki EE, Douagi I, Roth C, Colucci F, Cumano A, Di Santo JP. Identification of committed NK cell progenitors in adult murine bone marrow. Eur J Immunol (2001) 31:1900-9. doi:10.1002/1521-4141(200106)31:6<1900: :AID-IMMU1900>3.0.CO;2-M

4. Di Santo JP. Natural killer cell developmental pathways: a question of balance. Annu Rev Immunol (2006) 24:257-86. doi:10.1146/annurev.immunol.24. 021605.090700

5. Carotta S, Pang SH, Nutt SL, Belz GT. Identification of the earliest NK-cell precursor in the mouse BM. Blood (2011) 117:5449-52. doi:10.1182/blood-201011-318956

6. Fathman JW, Bhattacharya D, Inlay MA, Seita J, Karsunky H, Weissman IL. Identification of the earliest natural killer cell-committed progenitor in murine bone marrow. Blood (2011) 118:5439-47. doi:10.1182/blood-2011-04-348912

7. Chiossone L, Chaix J, Fuseri N, Roth C, Vivier E, Walzer T. Maturation of mouse NK cells is a 4-stage developmental program. Blood (2009) 113:5488-96. doi:10.1182/blood-2008-10-187179

8. Huntington ND, Tabarias H, Fairfax K, Brady J, Hayakawa Y, Degli-Esposti MA, et al. NK cell maturation and peripheral homeostasis is associated with KLRG1 up-regulation. J Immunol (2007) 178:4764-70.

9. Sciume G, De Angelis G, Benigni G, Ponzetta A, Morrone S, Santoni A, et al. CX3CR1 expression defines 2 KLRG1+ mouse NK-cell subsets with distinct functional properties and positioning in the bone marrow. Blood (2011) 117:4467-75. doi:10.1182/blood-2010-07-297101

10. Takeda K, Cretney E, Hayakawa Y, Ota T, Akiba H, Ogasawara K, et al. TRAIL identifies immature natural killer cells in newborn mice and adult mouse liver. Blood (2005) 105:2082-9. doi:10.1182/blood-2004-08-3262

11. Wu X, Chen Y, Wei H, Sun R, Tian Z. Development of murine hepatic NK cells during ontogeny: comparison with spleen NK cells. Clin Dev Immunol (2012) 2012:759765. doi:10.1155/2012/759765

12. Peng H, Jiang X, Chen Y, Sojka DK, Wei H, Gao X, et al. Liver-resident NK cells confer adaptive immunity in skin-contact inflammation. J Clin Invest (2013) 123:1444-56. doi:10.1172/JCI66381

13. Gordon SM, Chaix J, Rupp LJ, Wu J, Madera S, Sun JC, et al. The transcription factors T-bet and Eomes control key checkpoints of natural killer cell maturation. Immunity (2012) 36:55-67. doi:10.1016/j.immuni.2011.11.016

14. Vosshenrich CA, Garcia-Ojeda ME, Samson-Villeger SI, Pasqualetto V, Enault L, Richard-Le Goff O, et al. A thymic pathway of mouse natural killer cell development characterized by expression of GATA-3 and CD127. Nat Immunol (2006) 7:1217-24. doi:10.1038/ni1395

15. Stewart CA, Walzer T, Robbins SH, Malissen B, Vivier E, Prinz I. Germ-line and rearranged Tcrd transcription distinguish bona fide NK cells and NK-like gammadelta T cells. Eur J Immunol (2007) 37:1442-52. doi:10.1002/eji.200737354

16. Luevano M, Madrigal A, Saudemont A. Transcription factors involved in the regulation of natural killer cell development and function: an update. Front Immunol (2012) 3:319. doi:10.3389/fimmu.2012.00319

17. Huntington ND, Nutt SL, Carotta S. Regulation of murine natural killer cell commitment. Front Immunol (2013) 4:14. doi:10.3389/fimmu.2013.00014

18. Bezman NA, Cedars E, Steiner DF, Blelloch R, Hesslein DG, Lanier LL. Distinct requirements of microRNAs in NK cell activation, survival, and function. J Immunol (2010) 185:3835-46. doi:10.4049/jimmunol.1000980

19. Gascoyne DM, Long E, Veiga-Fernandes H, De Boer J, Williams O, Seddon $\mathrm{B}$, et al. The basic leucine zipper transcription factor E4BP4 is essential for natural killer cell development. Nat Immunol (2009) 10:1118-24. doi:10.1038/ ni. 1787

20. Boos MD, Yokota Y, Eberl G, Kee BL. Mature natural killer cell and lymphoid tissue-inducing cell development requires Id2-mediated suppression of E protein activity. J Exp Med (2007) 204:1119-30. doi:10.1084/jem.20061959
21. Kim S, Iizuka K, Kang HS, Dokun A, French AR, Greco S, et al. In vivo developmental stages in murine natural killer cell maturation. Nat Immunol (2002) 3:523-8. doi:10.1038/ni796

22. Jiang X, Chen Y, Peng H, Tian Z. Single line or parallel lines: NK cell differentiation driven by T-bet and Eomes. Cell Mol Immunol (2012) 9:193-4. doi:10.1038/cmi.2012.8

23. Bezman NA, Chakraborty T, Bender T, Lanier LL. miR-150 regulates the development of NK and iNKT cells. J Exp Med (2011) 208:2717-31. doi:10.1084/jem. 20111386

24. Trotta R, Chen L, Ciarlariello D, Josyula S, Mao C, Costinean S, et al. miR-155 regulates IFN-gamma production in natural killer cells. Blood (2012) 119:3478-85. doi:10.1182/blood-2011-12-398099

25. Zawislak CL, Beaulieu AM, Loeb GB, Karo J, Canner D, Bezman NA, et al. Stagespecific regulation of natural killer cell homeostasis and response against viral infection by microRNA-155. Proc Natl Acad Sci U S A (2013) 110:6967-72. doi: $10.1073 /$ pnas. 1304410110

26. Cichocki F, Felices M, McCullar V, Presnell SR, Al-Attar A, Lutz CT, et al. Cutting edge: microRNA-181 promotes human NK cell development by regulating Notch signaling. J Immunol (2011) 187:6171-5. doi:10.4049/ jimmunol.1100835

27. Bonecchi R, Galliera E, Borroni EM, Corsi MM, Locati M, Mantovani A. Chemokines and chemokine receptors: an overview. Front Biosci (Landmark Ed) (2009) 14:540-51. doi:10.2741/3261

28. Cyster JG, Schwab SR. Sphingosine-1-phosphate and lymphocyte egress from lymphoid organs. Annu Rev Immunol (2012) 30:69-94. doi:10.1146/annurevimmunol-020711-075011

29. Ma Q, Jones D, Borghesani PR, Segal RA, Nagasawa T, Kishimoto T, et al. Impaired B-lymphopoiesis, myelopoiesis, and derailed cerebellar neuron migration in CXCR4- and SDF-1-deficient mice. Proc Natl Acad Sci U S A (1998) 95:9448-53. doi:10.1073/pnas.95.16.9448

30. Zou YR, Kottmann AH, Kuroda M, Taniuchi I, Littman DR. Function of the chemokine receptor CXCR4 in haematopoiesis and in cerebellar development. Nature (1998) 393:595-9. doi:10.1038/31269

31. Egawa T, Kawabata K, Kawamoto H, Amada K, Okamoto R, Fujii N, et al. The earliest stages of $\mathrm{B}$ cell development require a chemokine stromal cell-derived factor/pre-B cell growth-stimulating factor. Immunity (2001) 15:323-34. doi: 10.1016/S1074-7613(01)00185-6

32. Tokoyoda K, Egawa T, Sugiyama T, Choi BI, Nagasawa T. Cellular niches controlling B lymphocyte behavior within bone marrow during development. Immunity (2004) 20:707-18. doi:10.1016/j.immuni.2004.05.001

33. Nagasawa T. Microenvironmental niches in the bone marrow required for B-cell development. Nat Rev Immunol (2006) 6:107-16. doi:10.1038/nri1780

34. Glodek AM, Honczarenko M, Le Y, Campbell JJ, Silberstein LE. Sustained activation of cell adhesion is a differentially regulated process in $\mathrm{B}$ lymphopoiesis. J Exp Med (2003) 197:461-73. doi:10.1084/jem.20021477

35. Glodek AM, Le Y, Dykxhoorn DM, Park SY, Mostoslavsky G, Mulligan R, et al. Focal adhesion kinase is required for CXCL12-induced chemotactic and pro-adhesive responses in hematopoietic precursor cells. Leukemia (2007) 21:1723-32. doi:10.1038/sj.leu.2404769

36. Palmesino E, Moepps B, Gierschik P, Thelen M. Differences in CXCR4-mediated signaling in B cells. Immunobiology (2006) 211:377-89. doi:10.1016/j.imbio. 2005.12.003

37. Bunting MD, Comerford I, McColl SR. Finding their niche: chemokines directing cell migration in the thymus. Immunol Cell Biol (2011) 89:185-96. doi:10.1038/icb.2010.142

38. Trampont PC, Tosello-Trampont AC, Shen Y, Duley AK, Sutherland AE, Bender TP, et al. CXCR4 acts as a costimulator during thymic beta-selection. Nat Immunol (2010) 11:162-70. doi:10.1038/ni.1830

39. Janas ML, Varano G, Gudmundsson K, Noda M, Nagasawa T, Turner M. Thymic development beyond beta-selection requires phosphatidylinositol 3-kinase activation by CXCR4. J Exp Med (2010) 207:247-61. doi:10.1084/jem. 20091430

40. Bunting MD, Comerford I, Seach N, Hammett MV, Asquith DL, Korner H, et al. CCX-CKR deficiency alters thymic stroma impairing thymocyte development and promoting autoimmunity. Blood (2013) 121:118-28. doi:10.1182/blood2012-06-434886

41. Germanov E, Veinotte L, Cullen R, Chamberlain E, Butcher EC, Johnston B. Critical role for the chemokine receptor CXCR6 in homeostasis and activation 
of CD1d-restricted NKT cells. J Immunol (2008) 181:81-91. doi:10.4049/ jimmunol.0803520

42. Bernardini G, Gismondi A, Santoni A. Chemokines and NK cells: regulators of development, trafficking and functions. Immunol Lett (2012) 145:39-46. doi:10.1016/j.imlet.2012.04.014

43. Walzer T, Chiossone L, Chaix J, Calver A, Carozzo C, Garrigue-Antar L, et al. Natural killer cell trafficking in vivo requires a dedicated sphingosine 1-phosphate receptor. Nat Immunol (2007) 8:1337-44. doi:10.1038/ni1523

44. Bernardini G, Sciume G, Bosisio D, Morrone S, Sozzani S, Santoni A. CCL3 and CXCL12 regulate trafficking of mouse bone marrow NK cell subsets. Blood (2008) 111:3626-34. doi:10.1182/blood-2007-08- 106203

45. Noda M, Omatsu Y, Sugiyama T, Oishi S, Fujii N, Nagasawa T. CXCL12-CXCR4 chemokine signaling is essential for NK-cell development in adult mice. Blood (2011) 117:451-8. doi:10.1182/blood-2010-04-277897

46. Mayol K, Biajoux V, Marvel J, Balabanian K, Walzer T. Sequential desensitization of CXCR4 and S1P5 controls natural killer cell trafficking. Blood (2011) 118:4863-71. doi:10.1182/blood-2011-06-362574

47. Weiss ID, Shoham H, Wald O, Wald H, Beider K, Abraham M, et al. Ccr5 deficiency regulates the proliferation and trafficking of natural killer cells under physiological conditions. Cytokine (2011) 54:249-57. doi:10.1016/j.cyto.2011. 01.011

48. Ponzetta A, Sciume G, Benigni G, Antonangeli F, Morrone S, Santoni A, et al. CX3CR1 regulates the maintenance of KLRG1+ NK cells into the bone marrow by promoting their entry into circulation. J Immunol (2013) 191:5684-94. doi:10.4049/jimmunol.1300090

49. Paust S, Gill HS, Wang BZ, Flynn MP, Moseman EA, Senman B, et al. Critical role for the chemokine receptor CXCR6 in NK cell-mediated antigenspecific memory of haptens and viruses. Nat Immunol (2010) 11:1127-35. doi:10.1038/ni.1953

50. Lisignoli G, Toneguzzi S, Pozzi C, Piacentini A, Grassi F, Ferruzzi A, et al. Chemokine expression by subchondral bone marrow stromal cells isolated from osteoarthritis (OA) and rheumatoid arthritis (RA) patients. Clin Exp Immunol (1999) 116:371-8. doi:10.1046/j.1365-2249.1999.00893.x

51. Hoshino A, Iimura T, Ueha S, Hanada S, Maruoka Y, Mayahara M, et al. Deficiency of chemokine receptor CCR1 causes osteopenia due to impaired functions of osteoclasts and osteoblasts. J Biol Chem (2010) 285:28826-37. doi:10.1074/jbc.M109.099424
52. Wald O, Weiss ID, Wald H, Shoham H, Bar-Shavit Y, Beider K, et al. IFN-gamma acts on $\mathrm{T}$ cells to induce NK cell mobilization and accumulation in target organs. J Immunol (2006) 176:4716-29.

53. Tano N, Kim HW, Ashraf M. microRNA-150 regulates mobilization and migration of bone marrow-derived mononuclear cells by targeting Cxcr4. PLoS One (2011) 6:e23114. doi:10.1371/journal.pone.0023114

54. Henao-Mejia J, Williams A, Goff LA, Staron M, Licona-Limon P, Kaech SM, et al. The microRNA miR-181 is a critical cellular metabolic rheostat essential for NKT cell ontogenesis and lymphocyte development and homeostasis. Immunity (2013) 38:984-97. doi:10.1016/j.immuni.2013.02.021

55. Jenne CN, Enders A, Rivera R, Watson SR, Bankovich AJ, Pereira JP, et al. T-betdependent S1P5 expression in NK cells promotes egress from lymph nodes and bone marrow. J Exp Med (2009) 206:2469-81. doi:10.1084/jem.20090525

56. Kee BL. E and ID proteins branch out. Nat Rev Immunol (2009) 9:175-84. doi:10.1038/nri2507

57. Jones-Mason ME, Zhao X, Kappes D, Lasorella A, Iavarone A, Zhuang Y. E protein transcription factors are required for the development of $\mathrm{CD} 4(+)$ lineage T cells. Immunity (2012) 36:348-61. doi:10.1016/j.immuni.2012.02.010

Conflict of Interest Statement: The authors declare that the research was conducted in the absence of any commercial or financial relationships that could be construed as a potential conflict of interest.

Received: 20 December 2013; accepted: 28 January 2014; published online: 13 February 2014.

Citation: Bernardini G, Benigni G, Antonangeli F, Ponzetta A and Santoni A (2014) Multiple levels of chemokine receptor regulation in the control of mouse natural killer cell development. Front. Immunol. 5:44. doi: 10.3389/fimmu.2014.00044

This article was submitted to NK Cell Biology, a section of the journal Frontiers in Immunology.

Copyright $\odot 2014$ Bernardini, Benigni, Antonangeli, Ponzetta and Santoni. This is an open-access article distributed under the terms of the Creative Commons Attribution License (CC BY). The use, distribution or reproduction in other forums is permitted, provided the original author(s) or licensor are credited and that the original publication in this journal is cited, in accordance with accepted academic practice. No use distribution or reproduction is permitted which does not comply with these terms. 